\title{
COVID-19 Pandemic Negatively Impacted Mental Health and Sports Participation of High School and Collegiate Athletes
}

\author{
Wentz Kyle $^{1 *}$, Milburn Nate ${ }^{2}$, Chhabra Avneesh ${ }^{1}$, Tietze David ${ }^{1}$ and Shah Jay $\mathbf{P}^{1}$ \\ ${ }^{1}$ Southwestern Medical Center, USA \\ ${ }^{2}$ University of Pennsylvania, USA
}

*Corresponding author: Wentz Kyle, Southwestern Medical Center, USA

\section{ARTICLE INFO}

Received: 幽 June 23, 2021

Published: 蔧 July 06, 2021

Citation: Wentz Kyle, Milburn Nate, Chhabra Avneesh, Tietze David, Shah Jay P. COVID-19 Pandemic Negatively Impacted Mental Health and Sports Participation of High School and Collegiate Athletes. Biomed J Sci \& Tech Res 37(1)-2021. BJSTR. MS.ID.005932.

Keywords: Mental Health; Covid-19; Sports Medicine; Detraining; Social Isolation

\section{ABSTACT}

Background: With current knowledge of the impact of social isolation and detraining, we sought to understand the impact of restrictions of the COVID-19 pandemic as they relate to competitive student athletes.

Hypothesis: The Covid-19 Pandemic has had a negative impact on the mental health of student athletes.

Study Design: Cohort Study

Level of Evidence: Level 4

Methods: A combined total of 409 college/graduate and high school student athletes responded to a survey with questions about demographics, sports participation, mental health, and physical activity.

Results: A total of $27 \%$ of college athletes and $29 \%$ of high school athletes felt they would return to sport at a lower level than previous training would have allowed with high school seniors $(\mathrm{P}=.000)$ and college seniors $(\mathrm{P}<.05)$ anticipating a return to sport at a statistically significant lower level of play when compared to other years. $36 \%$ of college athletes and $31.4 \%$ of high school athletes reported a negative impact of COVID-19 on their mental health with high school seniors reporting the most negative impact of the restrictions on their experience as student athletes $(\mathrm{P}<.05)$ when compared to other years. $63 \%$ of college athletes and $37.8 \%$ of high school athletes reported a negative impact of the restrictions on their overall experience as an amateur athlete. $83.1 \%$ of high school and $81 \%$ of college athletes reported adherence to COVID-19 related CDC guidelines with male college student athletes reporting slightly lower levels of adherence when compared to female college student athletes $(\mathrm{P}<.05)$

Conclusion: COVID-19 pandemic negatively impacted mental health of young athletes with the majority of collegiate and high school athletes anticipated returning to sport at a lower level of play, upon lifting of COVID-19 restrictions.

Clinical Relevance: Understanding how the COVID-19 pandemic impacts student athletes can lead to improvements in medical care for these athletes.

\section{Introduction}

In December of 2019 in Wuhan, Hubei Province, China, there arose an outbreak of a novel coronavirus (SARS-CoV-2) referred to as COVID-19. This virus quickly spread throughout the world causing a global health crisis [1,2]. In response to this pandemic, governments worldwide began to impose travel restrictions and quarantine of their citizens [3]. As this novel coronavirus and its 
mutants continue to spread rapidly, recommendations for its containment and prevention continue to develop [4]. Numbers of those tested and diagnosed with the illness continues to rise [5]. Not only has the pandemic created organizational and financial turmoil, but it has also had unprecedented effects on athletes and the world of sports [6,7]. With widespread social isolation measures in place, sporting events, team practices, and training facilities have largely been suspended or temporarily shut down [8]. The anticipated Olympic Games in Tokyo has also been postponed [8,9]. With continuing widespread restrictions, the athletes are unable to participate in their typical training regimens or competition [8].

These limitations can cause a negative impact on the mental and physical health of the competitive athlete [10-13] as many athletes are deprived of access to the needed equipment, facilities, and space to complete training regimens. Those who participate regularly at a high level of exercise and training are especially prone to exhibit negative mental health impacts [14]. The potential negative mental health effects of such disruption of daily life by quarantines and widespread social isolation on athletes include anxiety [15], depression [16,17], and insomnia [1]. In addition, athletes experience negative physical effects from being unable to participate in typical exercise routines. These include deconditioning [18,19], development of comorbid conditions [20], and decreased bone and muscular health [21]. Increased body fat percentage and rapid loss of exercise performance adaptations also occur in athletes who undertake a detraining period [22,23].

The effects of the COVID-19 pandemic and their impact on mental and physical health has been a largely speculated and intently studied topic since the pandemic began. Several studies have been performed assessing the COVID-19 pandemic's impact on mental health relating to various geographic populations [2428], in those with pre-existing mental health challenges [24], and in some specific populations such as college students $[29,30]$.
Studies have been performed prior to the pandemic but there is limited literature on evaluating athletes especially high-school and collegiate during the pandemic while social restrictions were in place. The purpose of this study was to retrospectively evaluate and highlight the impact of the COVID-19 pandemic and its accompanying widespread restrictions on the mental and physical health of the competitive high school and college student athletes using an in-house survey. We hypothesized that CDC restrictions and limited sports activity will significantly impact the athlete's mental health and level of play upon return.

\section{Materials and Methods}

\section{This was a HIPAA Compliant Local Institutional IRB Approved Study. The Survey was Anonymous and Voluntary}

Survey: A REDCAP survey (Figure 1) was prospectively sent to 424 college/graduate students and 1200 high school students. Questions about demographics, sports participation, mental health, and physical activity were included in the survey. In addition, further questions regarding compliance with $\mathrm{CDC}$ guidelines were included. Likert scales were used in compiling the results of the survey. A 3-point scale was used to measure responses as either "lower level", "same level", or "higher level" when asked about anticipated level of play upon return to sport. Similarly, A 5-point Likert scale was used for questions about adherence to CDC guidelines, home exercise programs, mental health, impact on future in their respective sports as seen in Figures 1-3. Survey participants were not involved in the design or dissemination plans of our research. All responses were completely anonymous for athlete privacy.

Statistics: All results were collated on a Microsoft Excel file (Windows 10, Redwood, Seattle). Statistical analysis was performed using IBM SPSS software, with t-test and ANOVA used to determine significance. P-value less than 0.05 was considered statistically significant. 


\section{Sports Medicine and COVID19}

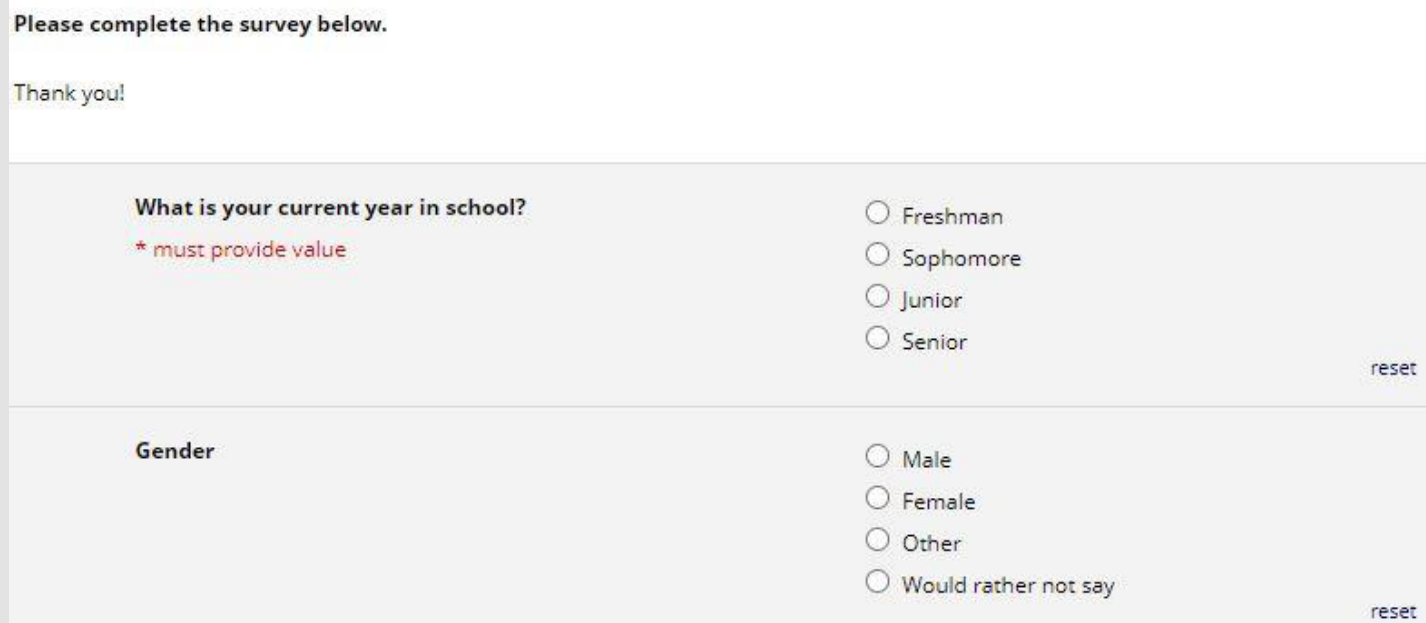

What is your primary sport?

* must provide value

What is the name of your school?

* must provide value

Are you currently rehabilitating an injury through a protocol given to you by a health care professional?
Yes
No
Unsure

Has a coach, athletic trainer, or other member of your official team reached out with a regimented exercise plan for use during the self isolation?

Yes

* must provide value

No

Unsure

How often have you participated in a home exercise program since self-isolation began?
Not at all
Very rarely
Sometimes
Frequently
Almost daily

Figure 1. 
In your opinion, how adequate are your home workouts at maintaining the level of fitness required for your sport?

Very poor

* must provide value

poor

Fair

Good

Excellent

reset

When quarantine ends, how likely are you to continue using this form of exercise on a regular basis?

* must provide value
Not at all
Very rarely
Sometimes
Frequently
Almost daily

Has the COVID outbreak had an effect on your mental health?

* must provide value
Very negatively
Somewhat negatively
Neutral
Somewhat Positively
Very Positively

reset

Once you return to sport, do you feel you will be able to play at a level similar to prior the self isolation?

* must provide value
Lower level
Same
Higher level

Do you believe self isolation will have an effect on your future regarding sports?

* must provide value
Very negatively
Somewhat negatively
Neutral
Somewhat positively
Very positively

reset
What overall effect has self isolation had on your personal experience as a collegiate athlete?
* must provide value
Very negative
Somewhat negative
Neutral
Somewhat Positive
Very Positive

Figure 2. 
To your knowledge, have you tested positive or had symptoms that you attribute to being infected with COVID 19?

* must provide value
Yes

No

Unsure

How closely have you followed the CDC guidelines for self quarantine (no groups larger than 5 people, not leaving the house other than for individual exercise or necessary home products like food/medicine, etc)

* must provide value

\section{Not at all \\ Very rarely \\ Sometimes \\ Frequently \\ All the time}

reset

Have you ever broken quarantine recommendations (no groups larger than 5 people, not leaving the house other than for individual exercise or necessary home products like

\section{Submit}

Figure 3.

\section{Results}

\section{Demographics}

Of the total sample, the majority ( $n=267 / 409,65 \%)$ were high school students, and roughly one third ( $n=142 / 409,35 \%)$ were college or college graduate students. The majority of college respondents $(n=83 / 142,58 \%)$ were female. The vast majority of high school respondents identified as female ( $n=180,68 \%)$. Among all class years of high school athletes, most were high school freshmen ( $n=106 / 267,40 \%)$. Table 1 lists detail of all demographics and different sports participations. Among all college respondents most $(n=44,31 \%)$ were freshmen and $(n=37) 26 \%$ were sophomores. Most college or high school athletes participated in soccer (87), softball (30), tennis (76), and volleyball (41) among others. Table 2 lists details of all demographics and different sports participations. Response rates for the survey were approximately $33 \%$ (142) for college graduates and 22\% (267) for high school students.

Table 1: Means of college student athlete survey responses regarding impact of COVID-19 related restrictions.

\begin{tabular}{|c|c|c|c|c|c|c|c|c|c|c|}
\hline Year & Count & Plan & $\begin{array}{c}\text { Home } \\
\text { Exercise }\end{array}$ & $\begin{array}{c}\text { Adequacy } \\
\text { of } \\
\text { Workout }\end{array}$ & $\begin{array}{c}\text { Continue } \\
\text { Use }\end{array}$ & $\begin{array}{l}\text { Mental } \\
\text { Health }\end{array}$ & $\begin{array}{l}\text { Level of } \\
\text { Play }\end{array}$ & Future & Experience & $\begin{array}{c}\text { Follow } \\
\text { CDC } \\
\text { Guidelines }\end{array}$ \\
\hline Fresh Man & $44,30.9 \%$ & 2.87 & 4.32 & 3.64 & 3.70 & 2.75 & $2.07^{*}$ & 2.82 & 2.32 & 4.07 \\
\hline Sophomore & $37,26.0 \%$ & 2.69 & 4.32 & 3.41 & 3.05 & 2.70 & $1.92^{*}$ & 2.92 & 2.22 & 4.05 \\
\hline Junior & $42,29.6 \%$ & 2.92 & 4.26 & 3.64 & 3.50 & 2.83 & $1.86^{*}$ & 2.88 & 2.36 & 4.31 \\
\hline Senior & $15,10.6 \%$ & 2.87 & 4.00 & 3.31 & 3.53 & 2.67 & $1.33^{*}$ & 2.40 & 2.53 & 4.20 \\
\hline Graduate & $4,2.8 \%$ & 2.50 & 4.00 & 3.50 & 4.00 & 2.25 & $2.25^{*}$ & 2.75 & 2.00 & 4.50 \\
\hline \multicolumn{11}{|c|}{ Gender } \\
\hline Male & $59,41.5 \%$ & 2.65 & 4.14 & 3.44 & $3.15^{*}$ & 2.85 & 1.98 & 2.92 & 2.25 & $3.98^{*}$ \\
\hline Female & $83,58.5 \%$ & 2.95 & 4.35 & 3.58 & $3.69 *$ & 2.66 & 1.83 & 2.75 & 2.36 & $4.29 *$ \\
\hline \multicolumn{11}{|c|}{ Sport } \\
\hline Base Ball & $8,5.6 \%$ & 2.17 & 3.50 & 3.13 & 2.25 & 3.13 & 1.88 & 2.88 & 2.75 & 3.75 \\
\hline Basketball & $19,13.4 \%$ & 3.12 & 4.42 & 3.53 & 3.32 & 3.11 & 2.05 & 2.84 & 2.58 & 3.89 \\
\hline $\begin{array}{l}\text { Stunt/ } \\
\text { Cheer }\end{array}$ & $18,12.7 \%$ & 2.63 & 4.44 & 3.67 & 3.89 & 2.72 & 1.94 & 2.72 & 2.22 & 4.50 \\
\hline $\begin{array}{l}\text { Cross } \\
\text { Country }\end{array}$ & $12,8.5 \%$ & 3.08 & 4.42 & 3.42 & 3.83 & 2.58 & 1.67 & 3.17 & 2.38 & 4.25 \\
\hline
\end{tabular}




\begin{tabular}{|c|c|c|c|c|c|c|c|c|c|c|}
\hline Golf & $12,8.5 \%$ & 2.40 & 3.58 & 3.08 & 3.42 & 2.92 & 1.83 & 3.08 & 2.00 & 3.83 \\
\hline Soccer & $43,30.3 \%$ & 3.03 & 4.42 & 3.65 & 3.47 & 2.53 & 2.05 & 2.74 & 2.14 & 4.19 \\
\hline Softball & $12,8.5 \%$ & 2.64 & 3.83 & 3.42 & 3.50 & 3.08 & 1.67 & 2.67 & 2.50 & 4.08 \\
\hline Tennis & $10,7.0 \%$ & 2.40 & 4.50 & 3.70 & 3.20 & 2.60 & 1.70 & 2.60 & 2.30 & 4.50 \\
\hline Volleyball & $8,5.6 \%$ & 3.14 & 4.50 & 3.63 & 3.88 & 2.25 & 1.63 & 2.88 & 2.50 & 4.38 \\
\hline${ }^{*}<<.05$ & & & & & & & & & \\
\hline
\end{tabular}

Table 2: Means of high school student athlete survey responses regarding impact of COVID-19 related restrictions.

\begin{tabular}{|c|c|c|c|c|c|c|c|c|c|c|}
\hline Year & Count & Plan & $\begin{array}{c}\text { Home } \\
\text { Exercise }\end{array}$ & $\begin{array}{c}\text { Adequacy } \\
\text { of } \\
\text { Workout }\end{array}$ & $\begin{array}{c}\text { Continue } \\
\text { Use }\end{array}$ & $\begin{array}{l}\text { Mental } \\
\text { Health }\end{array}$ & $\begin{array}{c}\text { Level of } \\
\text { Play }\end{array}$ & Future & Experience & $\begin{array}{l}\text { Follow } \\
\text { CDC } \\
\text { Guidelines }\end{array}$ \\
\hline Fresh Man & $106,39.7 \%$ & 2.76 & 3.86 & $3.75^{*}$ & 3.77 & 2.79 & $2.17^{*}$ & 2.94 & $2.93^{*}$ & 4.25 \\
\hline Sophomore & $68,25.5 \%$ & 2.74 & 4.01 & $3.65^{*}$ & 3.68 & 2.71 & $2.07^{*}$ & 2.87 & $2.76^{*}$ & 4.18 \\
\hline Junior & $58,21.7 \%$ & 2.75 & 3.79 & $3.29 *$ & 3.34 & 3.00 & $1.86^{*}$ & 2.88 & $2.66^{*}$ & 4.22 \\
\hline Senior & $35,13.1 \%$ & 2.84 & 3.97 & $3.37^{*}$ & 3.43 & 2.66 & $1.49^{*}$ & 2.89 & $2.29^{*}$ & 4.34 \\
\hline \multicolumn{11}{|c|}{ Gender } \\
\hline Male & $84,31.5 \%$ & 2.68 & 3.85 & 3.67 & 3.40 & 2.77 & 2.01 & 2.94 & 2.62 & 4.29 \\
\hline Female & $178,66.7 \%$ & 2.80 & 3.91 & 3.52 & 3.74 & 2.80 & 1.99 & 2.89 & 2.81 & 4.21 \\
\hline $\begin{array}{c}\text { Other/ } \\
\text { Would } \\
\text { Rather Not } \\
\text { Say }\end{array}$ & $5,1.9 \%$ & 3.00 & 4.40 & 4.00 & 3.40 & 3.20 & 1.60 & 2.80 & 2.60 & 2.00 \\
\hline \multicolumn{11}{|c|}{ Sport } \\
\hline Base Ball & $2, .75 \%$ & 3.00 & 4.00 & 4.00 & 4.50 & 3.50 & 1.50 & 2.50 & 2.00 & 3.50 \\
\hline Basketball & $11,4.1 \%$ & 2.78 & 3.82 & 3.18 & 3.18 & 2.73 & 2.09 & 2.18 & 2.18 & 4.55 \\
\hline Bowling & $1, .37 \%$ & 2.00 & 3.00 & 3.00 & 2.00 & 3.00 & 1.00 & 3.00 & 2.00 & 3.00 \\
\hline Cheer & $1, .37 \%$ & 3.00 & 3.00 & 4.00 & 3.00 & 2.00 & 2.00 & 3.00 & 3.00 & 4.00 \\
\hline $\begin{array}{l}\text { Cross } \\
\text { Country }\end{array}$ & $12,4.5 \%$ & 3.00 & 3.92 & 3.50 & 3.83 & 2.83 & 1.33 & 2.83 & 2.92 & 4.25 \\
\hline Football & $52,19.5 \%$ & 2.70 & 4.02 & 3.75 & 3.44 & 2.67 & 2.35 & 3.10 & 2.65 & 4.19 \\
\hline Soccer & $44,16.5 \%$ & 2.73 & 4.14 & 3.73 & 3.82 & 2.98 & 2.20 & 3.20 & 2.93 & 2.00 \\
\hline Softball & $18,6.7 \%$ & 2.56 & 4.06 & 3.67 & 3.44 & 2.33 & 2.28 & 2.56 & 2.98 & 2.00 \\
\hline Swim & $8,3 \%$ & 3.13 & 4.00 & 3.50 & 3.75 & 2.88 & 1.25 & 2.25 & 2.25 & 2.00 \\
\hline Tennis & $66,24.7 \%$ & 2.68 & 3.64 & 3.41 & 3.47 & 3.02 & 1.70 & 2.94 & 2.80 & 2.09 \\
\hline $\begin{array}{l}\text { Track and } \\
\text { Field }\end{array}$ & $17,6.4 \%$ & 2.71 & 3.76 & 3.35 & 4.06 & 2.71 & 1.94 & 2.82 & 2.88 & 2.00 \\
\hline Volleyball & $33,12.4 \%$ & 3.00 & 3.91 & 3.58 & 3.88 & 2.64 & 2.03 & 2.79 & 2.58 & 2.03 \\
\hline Wrestling & $2, .75 \%$ & 4.00 & 4.50 & 4.50 & 4.50 & 2.00 & 2.00 & 3.00 & 4.00 & 2.00 \\
\hline$* \mathrm{P}<.05$ & & & & & & & & & & \\
\hline
\end{tabular}

\section{Adherence to CDC Guidelines}

The vast majority of high school (83.1\%) and college (81\%) student athletes reported that they follow CDC guidelines "frequently" or "all the time". There was a statistically significant difference between male and female college student athletes who reported on their adherence levels to the CDC guidelines $(\mathrm{P}<.05)$ with males (3.98) reporting lower levels of adherence than females (4.29).

\section{Workouts and Ability to Return to Sport}

Among the college athletes, the vast majority (91\%) reported that a team staff member had reached out to them with an exercise plan to use during the time of CDC guided restrictions. Most (77\%) reported using a home exercise plan frequently or almost daily. Just over half (54\%) of college respondents felt that their home exercise program was good or excellent. Although just under half (49\%) admitted that they planned to use the regimen frequently or almost 
daily upon lifting of the CDC guidelines. There was a statistically significant difference between male and female athletes in their plans to continue using their current home exercise programs $(\mathrm{P}<.01)$. Females felt more likely (3.69) compared to males (3.15) to continue using their current home exercise programs. Females (1.83) on average anticipated very slightly lower levels of play upon return to sport than males (1.98). There was a statistically significant difference between athletes based on their year in college and anticipated level of play upon return to sport ( $\mathrm{P}=.003)$.

College seniors (1.33) reported the lowest anticipated levels of play upon return while college graduates (2.25) reported the highest anticipated levels of play upon return to sport following alleviation of CDC guided restrictions. Generally, more (27\%) college athletes felt they would return to play at a lower level than those (17\%) who felt they would return at a higher level of play upon return to sport. Among high school athletes, the vast majority (88\%) reported that a team staff member had reached out to them with an exercise plan to use during the time of CDC guided restrictions. Two thirds (68.2\%) of high school athletes reported using a home exercise program frequently or almost daily. Roughly the same percentage of high school athletes felt they would return to sport at a lower level $(29 \%, n=78)$ after the restrictions had ended compared with those who felt they would return to sport at a higher level of play $(29 \%, n=75)$. Almost half $(43 \%, n=114)$ of high school athletes said they were neutral with regards to anticipated level of play upon return to sport. There were also statistically significant differences between athletes of different high school class years reporting anticipated level of play upon return to sport $(\mathrm{P}=.000)$ with high school seniors (1.49) reporting an anticipated return to play at the lowest levels and freshmen (2.17) anticipating a return to play at the highest levels among all class years.

High school Juniors and Seniors also reported feeling their home based workouts were inadequate $(\mathrm{P}<.05)$ when compared to other years. Almost one third (29.2\%) overall felt they would return to play at a lower level following the period of CDC guided restrictions. There were also statistically significant class year differences between athletes' responses for whether they felt their exercise program was adequate $(\mathrm{P}=.003)$. Using a five point likert scale, high school freshmen (3.75) and sophomore (3.65) athletes reported more optimism that their exercise programs were adequate compared to juniors (3.29) and seniors (3.37). Overall, roughly half $(54.7 \%)$ of athletes reported that their home exercise programs were good or excellent and $57.7 \%$ said they would continue to use their exercise program frequently or almost daily once CDC guided restrictions were lifted.

\section{Mental Health}

Among college athletes, very few (11\%) expressed a positive impact of COVID-19 related restrictions on their mental health. The majority (54\%) expressed a neutral impact, while roughly one third (36\%) expressed a negative impact of the restrictions on their mental health. Most (63\%) college respondents reported a negative impact of the restrictions on their experience as college athletes while more than one fourth (28\%) felt the restrictions would have a negative impact on their future in sports. Among high school athletes, almost one third $(31.4 \%)$ reported a negative impact of the social isolation and COVID related restrictions on their mental health. Using a five point Likert scale, there were sport specific statistically significant differences $(\mathrm{P}<.05)$ for athletes who felt the restrictions would have an impact on their future in sports with soccer players responding most positively (3.2) and basketball players feeling the most negative impact on their futures (2.18).

Essentially one third (31.5\%) felt the current restrictions would have a negative impact on their future as an athlete. There were statistically significant differences between athletes of different high school class years who reported an impact of the restrictions on their overall experience as a high school athlete $(\mathrm{P}=.001)$ with seniors (2.29) reporting the most negative impact on their experience. Among all class years, roughly one third (37.8\%) felt the restrictions had a negative impact on their overall experience as a high school athlete. This percentage of high school athletes reporting a negative impact of the restrictions on their experience as a high school athlete is much lower than the $63 \%$ of college athletes who similarly reported a negative impact of the restrictions on their experiences as college student athletes.

\section{Discussion}

Maintenance of a structured workout program for high level athletes is paramount for continued success in sport. It is not surprising to these authors that most athletes surveyed were in discussions with team staff members about a home exercise program during the pandemic. With limited access to advanced training equipment, it is understandable why $27 \%$ of collegiate and $29 \%$ of high school athletes felt they would return to their sport at a lower level than their previous training would have allowed. Knowledge and experience of these structured programs with specific training facilities would also explain the class discrepancy in perception of home training programs. A unique perspective from this study was on the mental health of the athletes surveyed. It is unfortunate that most collegiate athletes surveyed (63\%) noted a negative impact on their collegiate athlete experience. It is possible that for most of these athletes, their participation in this level of athletics is limited and each season spent without competition is a season lost. However, it should be noted that the NCAA has made some accommodations to help reclaim these seasons by issuing a policy that seniors missing the season from last spring may regain their eligibility.

It is also with saddened understanding that we see high school seniors reporting the pandemic's effect on their experience negatively as many of them will have a premature end to their 
athletic career. Although the high school athletes surveyed were more optimistic regarding their future in athletics when compared to collegiate athletes, there is no question that the COVID 19 pandemic has had an impact on the mental health of both athlete populations. This would be an ideal area for additional research in the Sports Medicine community. The majority of both athlete populations seem to have adhered to the CDC recommendations with only minimal deviation for sports related activities. This is in contrast to a perception that members of this age group were routinely disregarding $\mathrm{CDC}$ guidelines for selfish benefit. A possible explanation is that the athletes surveyed were more disciplined than their non-athletic counterparts. Another is that the initial perception of disobedience in these young men and women is inaccurate and should not be applied to them en masse. It is, however, comforting to know that despite wavering confidence in medical leadership throughout this pandemic that many of the young athletes surveyed were practicing measures to keep their community safe. One of the potential sources for bias in this study is that of selection.

Although attempts were made to encourage the athletes to participate through two separate email reminders and the anonymous nature of the survey itself, the study is only subject to those participants that chose to respond. With a $n=4$, it is unlikely that the results evaluated for graduate students would yield enough power to make specific analysis accurate to that group. Additionally, all of the athletes survived were in the Dallas Metroplex region. Further analysis would be needed in other areas (either nationally or internationally) to give a more general understanding of COVID 19 repercussions on athletes. Another potential bias includes that of recall as $\mathrm{CDC}$ recommendations were adapting to the prevalence of the pandemic. Although the majority of athletes felt they were compliant with CDC guidelines during the pandemic, they may have been evaluating their previous activity with updated recommendations. It should also be noted that the survey was taken after the first surge in the Dallas area. Further analysis may need to be done to see if these trends hold to this population especially after the second surge was noted in Texas during the summer months. Finally, as the authors do not have any financial interests to disclose, we do not feel there was bias in the analysis of this data.

\section{Conclusion}

To conclude, COVID-19 pandemic negatively impacted mental health of young athletes with most of collegiate and high school athletes anticipated returning to sport at a lower level of play, upon lifting of COVID-19 restrictions.

\section{Conflict of Interest Statements}

The authors have no conflicts of interest to disclose.

\section{References}

1. Ahmed MZ, Ahmed O, Aibao Z, Hanbin S, Siyu L (2020) Epidemic of COVID-19 in China and associated Psychological Problems. Asian J Psychiatr 51: 102092.

2. Araujo FJO, De Lima LSA, Cidade PIM, Nobre CB, Neto MLR (2020) Impact of Sars-Cov-2 And Its Reverberation In Global Higher Education And Mental Health. Psychiatry Res 288: 112977.

3. Baig M, Jameel T, Alzahrani SH, Mirza AA, Gazzaz ZJ (2020) Predictors of misconceptions, knowledge, attitudes, and practices of COVID-19 pandemic among a sample of Saudi population. PLoS One 15(12): e0243526.

4. Banerjee D, Rai M (2020) Social isolation in Covid-19: The impact of loneliness. Int J Soc Psychiatry 66(6): 525-527.

5. Chatterjee SS, Barikar CM, Mukherjee A (2020) Impact of COVID-19 pandemic on pre-existing mental health problems. Asian J Psychiatr 51: 102071 .

6. Chen P, Mao L, Nassis G, Harmer P, Ainsworth B (2020) Coronavirus disease (COVID-19): The need to maintain regular physical activity while taking precautions. J Sport Health Sci 9(2): 103-104.

7. Chew QH, Wei KC, Vasoo S, Chua HC, Sim K (2020) Narrative synthesis of psychological and coping responses towards emerging infectious disease outbreaks in the general population: practical considerations for the COVID-19 pandemic. Singapore Med J 61(7): 350-356.

8. Corsini A, Bisciotti GN, Eirale C, Volpi P (2020) Football cannot restart soon during the COVID-19 emergency! A critical perspective from the Italian experience and a call for action. Br J Sprots Med 54(20): 11861187.

9. Gallego V, Nishiura H, Sah R, Rodriguez Morales AJ (2020) The COVID-19 outbreak and implications for the Tokyo 2020 Summer Olympic Games. Travel Med Infect Dis 34: 101604.

10. García Pallarés J, Sanchez Medina L, Pérez CE, Izquierdo Gabarren M, Izquierdo M (2010) Physiological effects of tapering and detraining in world-class kayakers. Med Sci Sports Exerc 42(6): 1209-1214.

11. Gloster AT, Lamnisos D, Lubenko J, Presti G, Squatrito V, et al. (2020) Impact of COVID-19 pandemic on mental health: An international study. PLoS One 15(12): e0244809.

12. https://www.ncaa.org/about/resources/media-center/news/division-i-council-extends-eligibility-student-athletes-impacted-covid-19

13. Islam MS, Sujan MSH, Tasnim R, Sikder MT, Potenza MN (2020) Psychological responses during the COVID-19 outbreak among university students in Bangladesh. PLoS One 15(12): e0245083.

14. Jakov ljevic M (2020) COVID-19 Crisis as a Collective Hero's Journey to Better Public and Global Mental Health. Psychiatr Danub 32(1): 3-5.

15. Jukic I, Calleja Gonzalez J, Cos F (2020) Strategies and Solutions for Team Sports Athletes in Isolation due to COVID-19. Sports (Basel) 8(4): 56.

16. Koundourakis NE, Androulakis NE, Malliaraki N, Tsatsanis C, Venihaki M (2014) Discrepancy between exercise performance, body composition, and sex steroid response after a six-week detraining period in professional soccer players. PLoS One 9(2): e87803.

17. Malboeuf Hurtubise C, Léger Goodes T, Mageau GA, Joussemet M, Herba $C$, et al. (2021) Philosophy for children and mindfulness during COVID-19: Results from a randomized cluster trial and impact on mental health in elementary school students. Prog Neuropsychopharmacol Biol Psychiatry 107: 110260.

18. Neufer PD, Costill DL, Fielding RA, Flynn MG, Kirwan JP (1987) Effect of reduced training on muscular strength and endurance in competitive swimmers. Med Sci Sports Exerc 19(5): 486-490. 
19. Owens DJ, Allison R, Close GL (2018) Vitamin D and the athlete: current perspectives and new challenges. Sports Med 48(1): 3-16.

20. Rajkumar RP (2020) COVID-19 and mental health: A review of the existing literature. Asian J Psychiatr 52: 102066.

21. Shaygan M, Yazdani Z, Valibeygi A (2021) The effect of online multimedia psychoeducational interventions on the resilience and perceived stress of hospitalized patients with COVID-19: a pilot cluster randomized parallel-controlled trial. BMC Psychiatry 21(1): 93.

22. Sohrabi C, Alsafi Z, O Neill N (2020) World Health Organization declares global emergency: A review of the 2019 novel coronavirus (COVID-19). Int J Surg 76: 71-76.

23. Sousa AC, Neiva HP, Izquierdo M, Cadore EL, Alves AR (2019) Concurrent Training and Detraining: brief Review on the Effect of Exercise Intensities. Int J Sports Med 40(12): 747-755.

24. Toresdahl BG, Asif IM (2020) Coronavirus Disease 2019 (COVID-19): Considerations for the Competitive Athlete. Sports Health 12(3): 221224.

25. Vanden Bossche D, Lagaert S, Willems S, Decat P (2021) Community Health Workers as a Strategy to Tackle Psychosocial Suffering Due to Physical Distancing: A Randomized Controlled Trial. Int J Environ Res Public Health 18(6): 3097.

\section{ISSN: 2574-1241}

DOI: $10.26717 /$ BJSTR.2021.37.005932

Wentz Kyle. Biomed J Sci \& Tech Res

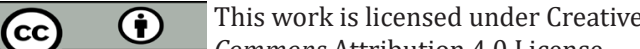
Commons Attribution 4.0 License

Submission Link: https://biomedres.us/submit-manuscript.php
26. Zhai Y, Du X (2020) Addressing collegiate mental health amid COVID-19 pandemic. Psychiatry Res 288: 113003.

27. Zhang J, Lu H, Zeng H (2020) The differential psychological distress of populations affected by the COVID-19 pandemic. Brain Behav Immun 87: 49-50.

28. Zhang SX, Wang Y, Rauch A, Wei F (2020) Unprecedented disruption of lives and work: Health, distress and life satisfaction of working adults in China one month into the COVID-19 outbreak. Psychiatry Res 288: 112958.

29. Zhang Y, Ma ZF (2020) Impact of the COVID-19 Pandemic on Mental Health and Quality of Life among Local Residents in Liaoning Province, China: A Cross-Sectional Study. Int J Environ Res Public Health 17(7): 2381.

30. Zhu S, Wu Y, Zhu CY (2020) The immediate mental health impacts of the COVID-19 pandemic among people with or without quarantine managements. Brain Behav Immun 87: 56-58.

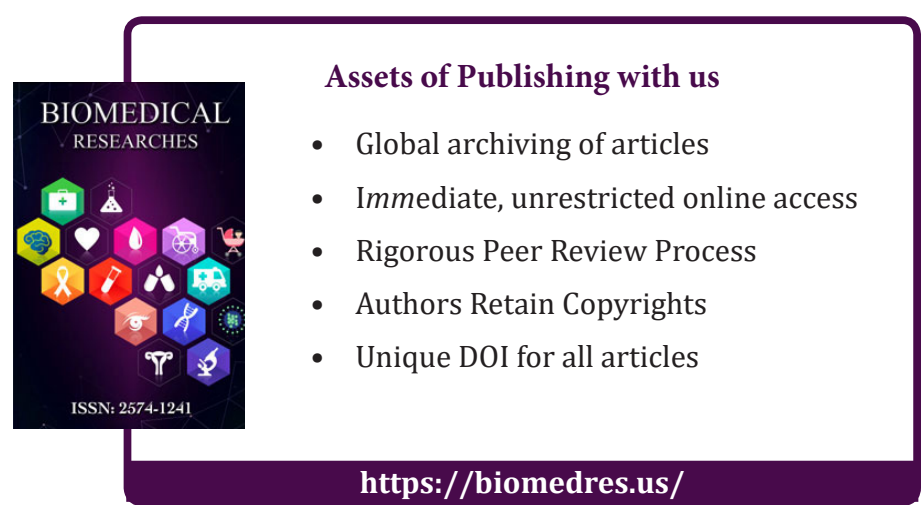

